\title{
Editorial for Ocean Reanalysis Intercomparison Special Issue
}

\author{
ORAIP-v1: the ocean reanalyses intercomparison project version 1
}

\author{
Magdalena Alonso Balmaseda ${ }^{1}$
}

Published online: 4 August 2017

(c) Springer-Verlag GmbH Germany 2017

There is increasing demand for historical records of the ocean climate. These are needed as a reference for monitoring the current state of the climate, and also to initialise and validate long-range (e.g. seasonal to decadal) forecasts. Observations alone are often inadequate to generate the required estimate of the ocean variables. Ocean model simulations can provide some insight on the ocean variability, but they are affected by biases due to errors in model formulation, specification of initial states and forcing, and are not directly constrained by observations. Ocean reanalyses are the combination of ocean models, atmospheric forcing fluxes and ocean observations via data assimilation methods and have the potential to provide more accurate information than observation-only or model-only based ocean estimations.

The production of ocean reanalyses (ORAs hereafter) is now an established activity in several research and operational centres. ORAs are revisited every so often, and new 'vintages' are produced at intervals of about 5 years, as improvements in ocean models, data assimilation methods, forcing fluxes or ocean observations become available.

There is need for routine coordinated evaluation of ORAs, which would exploit the existing reanalyses products for a variety of purposes, namely (1) identification of robust climate signals and associated uncertainty, (2) measuring progress in the quality of the reanalyses, (3) producing indices for ocean monitoring with associated error estimates, (4) identification of main deficiencies to guide future developments. These are the motivations for ongoing Ocean Reanalyses Intercomparison Project (ORAIP), initiated by the CLIVAR and GODAE-Ocean View communities.

This special issue is concerned with reanalyses produced around 2010, and compiles the main coordinated analyses carried out under the ORAIPv1 initiative. The studies herein attempt to measure the maturity of the climate information provided by the current generation ocean reanalyses in terms of signal-to-noise ratios of selected variables, such as ocean heat content, steric sea level, mixed layer depth, ocean salinity, surface fluxes over the ocean, sea-ice variables, Atlantic meridional overturning circulation, among others. The ensemble of ocean reanalyses can be exploited for real-time ocean monitoring, for the evaluation of the observing system, or for the initialization of seasonal forecasts, as it is illustrated by some contributions within this SI. Some other contributions report on specific features of ocean reanalyses at eddy-permitting resolution, and discuss important sensitivities within a particular ocean reanalysis system which help to identify current deficiencies and guide future developments.

The overview of this project is summarized in Balmaseda et al. (2015). The previous vintage of ORAs (produced around 2006) has already been documented (Stammer et al. 2010), and we will refer to it as ORAIPv0. At the time of writing, a new vintage of ocean reanalyses is being produced (vintage 2016), which hopefully addresses some of the identified deficiencies, and will in time become be the subject of the second version of the intercomparison (ORAIPv2).

Magdalena Alonso Balmaseda

magdalena.balmaseda@ecmwf.int

1 European Center for Medium Range Weather Forecasts, Shinfield Park, Reading RG2 9AX, UK 


\section{References}

Balmaseda MA, Hernandez F, Storto A, Palmer MD, Alves O, Shi L, Smith GC, Toyoda T, Valdivieso M, Barnier B, Behringer D (2015) The ocean reanalyses intercomparison project (ORA-IP). J Oper Oceanogr 8(supp 1):s80-s97
Stammer D, Köhl A, Awaji T, Balmaseda M, Behringer D, Carton J, Ferry N, Fischer A, Fukumori I, Gise B, Haines K (2010) Ocean information provided through ensemble ocean syntheses. In: OceanObs 09. European Space Agency, pp 979-989 